\section{Psicologia Escolar \\ e Educacional}

ARTIGO

DOI: http://dx.doi.org/10.1590/2175-35392021227839

Localizador - e227839

\title{
CARACTERIZAÇÃO DAS RELAÇÕES INTERPESSOAIS ENTRE ALUNOS COM DEFICIÊNCIA INTELECTUAL E SEUS PARES
}

\author{
Mary Cristina Olimpio Pinheiro ' ${ }^{\mathbb{D}}$; Aline Maira da Silva ${ }^{1} \mathbb{D}$; Eladio Sebastián-Heredero ${ }^{2} \mathbb{D}$
}

\begin{abstract}
RESUMO
O objetivo da pesquisa foi descrever e analisar as relações interpessoais entre alunos com deficiência intelectual (DI) e seus colegas de sala de aula em contextos escolares inclusivos. Trata-se de pesquisa quantitativa e qualitativa realizada em salas dos primeiros anos do Ensino Fundamental. Foram levantados indicadores da participação do aluno com DI nas relações interpessoais, por meio de entrevistas junto a 268 alunos, sendo $13 \mathrm{com}$ DI. A partir desses resultados, seis alunos com DI foram eleitos como alvo em sessões de observação sistemática. Observou-se que as relações interpessoais sofreram influência: da atuação das professoras regentes e dos apoios educacionais; da competência social dos alunos com DI e das características dos mesmos; do ambiente da sala de aula. Acredita-se que, por meio do investimento na promoção de habilidades sociais na escola, será possível contribuir para a construção de um ambiente propício a práticas educacionais inclusivas.
\end{abstract}

Palavras-chave: relações interpessoais; habilidades sociais; inclusão escolar

\section{Characterizations of interpersonal relations between students with intelectual disabilities and their peers}

\begin{abstract}
The aim of the research was to describe and analyze the interpersonal relationships between students with intellectual disabilities (ID) and their classroom colleagues in inclusive school contexts. This is a quantitative and qualitative research carried out in classrooms in the first years of elementary school. Indicators of the students with ID participation in interpersonal relationships were raised through interviews with 268 students, 13 with ID. From these results, six students with ID were chosen as targets in systematic observation sessions. It was observed that interpersonal relationships were influenced by: the role of the regent teachers and educational support; the ID students' social competence and their characteristics; the classroom environment. It is believed that, through investment in the promotion of social skills at school, it will be possible to contribute to the construction of an appropriate environment to inclusive educational practices.
\end{abstract}

Keywords: interpersonal relationships; social skills; school inclusion

\section{Caracterización de las relaciones interpersonales entre alumnos con deficiencia intelectual y sus pares}

\section{RESUMEN}

El objetivo de la investigación fue describir y analizar las relaciones interpersonales entre alumnos con deficiencia intelectual (DI) y sus compañeros de sala de clase en contextos escolares inclusivos. Se trata de investigación cuantitativa y cualitativa realizada en salas de los primeros cursos de la enseñanza básica. Se recompilaron indicadores de la participación del alumno con DI en las relaciones interpersonales, por intermedio de entrevistas junto a 268 alumnos, 13 con DI. A partir de esos resultados, seis alumnos con DI fueron electos como diana en sesiones de observación sistemática. Se tuvo por observo que las relaciones interpersonales sufrieron influencia: de la actuación de las profesoras regentes y de los apoyos educacionales; de la competencia social de los alumnos con DI y de las características de ellos; del ambiente de la sala de clase. Se cree que, por intermedio de la inversión en la promoción de habilidades sociales en la escuela, será posible contribuir para la construcción de un ambiente propicio a las prácticas educacionales inclusivas.

Palabras clave: relaciones interpersonales; habilidades sociales; inclusión escolar

$\overline{1}$ Universidade Federal da Grande Dourados - Dourados - MS - Brasil; mary.c.pinheiro@hotmail.com; alinesilva@ufgd.edu.br

${ }^{2}$ Universidade Federal De Mato Grosso do Sul - Campo Grande - MS - Brasil; eladio.sebastian@gmail.com 


\section{INTRODUÇÃO}

A inclusão escolar é amplamente discutida nos dias atuais, assim como o debate sobre como buscar e implementar meios para efetivação desse processo. Apesar da literatura da área apontar benefícios proporcionados pela inclusão escolar, ainda é possível observar muitos obstáculos para que tal processo seja efetivado de maneira bem-sucedida. Por exemplo, muitos alunos com deficiência matriculados na rede regular ainda vivenciam situações de preconceito que prejudicam o seu desenvolvimento e dificultam sua aprendizagem.

O desenvolvimento de competência na educação é um tema novo no Brasil, incorporado pela Base Nacional Comum Curricular - BNCC (MEC, 2017, p. 6): “Competência é definida como a mobilização de conhecimentos (conceitos e procedimentos), habilidades (práticas, cognitivas e socioemocionais), atitudes e valores para resolver demandas complexas da vida cotidiana, do pleno exercício da cidadania e do mundo do trabalho".

Por outro lado, o tema em questão já vinha sendo trabalhado há muitos anos, conforme DeSeCo (2016), que já incluía entre as três competências fundamentais a interação social em grupos heterogêneos dentro das conhecidas competências não cognitivas ou socioemocionais, que concretamente na BNCC se definem na forma de relações interpessoais.

Exercitar a empatia, o diálogo, a resolução de conflitos e a cooperação, fazendo-se respeitar e promovendo o respeito ao outro e aos direitos humanos, com acolhimento e valorização da diversidade de indivíduos e de grupos sociais, seus saberes, identidades, culturas e potencialidades, sem preconceitos de qualquer natureza. (MEC, 2017, p. 8).

Segundo apontam Del Prette e Del Prette (2005), o estabelecimento dessas relações interpessoais é uma das principais tarefas para o desenvolvimento das crianças, uma vez que é a partir dessas relações que se ampliam e aprimoram uma série de comportamentos sociais, assim como se aprende como é o funcionamento da vida em sociedade.

No caso dos alunos com deficiência intelectual (DI), matriculados no sistema regular de ensino inclusivo, a questão da competência social é ainda mais crucial. Conforme apontam Rosin-Pinola, Del Prette e Del Prette (2007), os principais desafios relacionados com a inclusão escolar dos alunos com DI residem não apenas no desempenho acadêmico abaixo da média, mas também nas dificuldades de estabelecer boas relações com os colegas. Conforme Sebastián-Heredero (2016), de forma geral o desenvolvimento de competências poderia ser resolvido a partir da adoção de um currículo inclusivo: "Tal vez los planteamientos de un currículo inclusivo comiencen por ofrecer algo que sea útil para ellos y aplicable en su día a día y de hecho se está trabajando en ello: son las llamadas competencias básicas" (p. 19).

Batista e Enumo (2004) realizaram um estudo com o objetivo de descrever e analisar as relações interpessoais de três alunos com DI e seus colegas de três turmas da primeira série do ensino fundamental. Foram aplicados testes sociométricos com os 80 alunos das salas de aulas selecionadas, nas quais estavam matriculados alunos com DI. Entre os resultados, Batista e Enumo (2004) concluíram que os três alunos com DI matriculados nas turmas investigadas demonstraram maior dificuldade para iniciar, manter e finalizar contatos sociais com seus colegas, o que resultou com que os mesmos fossem ignorados pelos mesmos.

Rosin-Pinola et al. (2007) desenvolveram um estudo cujo objetivo foi avaliar o repertório de habilidades sociais e de rendimento acadêmico, em classes nas quais alunos com DI estavam matriculados. Para tanto, os alunos participantes foram divididos em três grupos: alto rendimento acadêmico (AR), baixo rendimento acadêmico (BR) e alunos com deficiência mental (DM). Trinta professores responderam a questionários do Sistema de Avaliação de Habilidades Sociais, referentes a 120 alunos. Os dados foram analisados estatisticamente.

Como resultado principal, Rosin-Pinola et al. (p. 247, 2007) observaram que tanto o grupo $B R$ quanto o DM tiveram baixos escores em habilidades como "responsabilidade" e "autocontrole e cooperação com os pares" que são essenciais para o sucesso acadêmico. Outro resultado importante da pesquisa foi que o grupo com deficiência mental "gosta de ficar sozinho" e apresentou mais dificuldades para fazer amizades e se integrar ao grupo de colegas devido ao comprometimento de suas habilidades sociais.

Freitas e Mendes (2009) realizaram uma pesquisa com o objetivo de analisar as relações interpessoais por meio do estudo das interações entre uma criança com Síndrome de Down e seus 14 colegas, em uma creche regular na cidade de São Carlos, SP. Para alcançar o objetivo proposto, foram realizadas cinco sessões de filmagens de situações naturais de brincadeira livre. As gravações foram analisadas a partir de um protocolo, por meio do qual os comportamentos interativos apresentados pelas crianças com Síndrome de Down e seus pares eram avaliados.

Como resultado, as autoras observaram que a criança com Síndrome de Down permaneceu a maior parte do tempo isolada em relação aos seus colegas. Além disso, as interações que estabeleciam com seus pares eram menores e de qualidades diferentes quando comparadas às interações entre as demais crianças sem deficiências. Os comportamentos interativos estabelecidos no ambiente escolar pela criança com Síndrome de Down eram em sua maioria apenas presentes na relação aluno-professor. 
Como evidenciado nos estudos apresentados, apesar da inclusão escolar proporcionar ganhos sociais e acadêmicos, as relações interpessoais estabelecidas entre os alunos com deficiência e seus pares não são significativas e os primeiros ainda passam grande parte do seu tempo sozinhos. Isso faz com que os alunos com deficiência tenham poucas oportunidades para desenvolver e aprimorar suas habilidades sociais o que dificulta o processo de ensino e aprendizagem.

Em vista disso, o presente estudo partiu da seguinte questão norteadora: como as relações interpessoais entre os alunos com DI e seus pares estão sendo estabelecidas nas salas de aula do ensino regular? 0 objetivo geral do estudo foi descrever e analisar as relações interpessoais entre alunos com DI e seus colegas de sala de aula, em escolas de ensino fundamental.

\section{MÉTODO}

O estudo foi realizado em três escolas municipais localizadas na cidade de Dourados/MS, denominadas com as letras A, B e C. O delineamento do estudo compreendeu duas etapas: 1) pesquisa de levantamento e 2) observação sistemática de comportamentos.

\section{$1^{\circ}$ Etapa: Pesquisa de Levantamento}

Participaram da primeira etapa do estudo 13 alunos com DI (A1; A2; A3; A4; A5; A6; A7; A8; A9; A10; A11; A12; A13), assim como todos os seus colegas de sala de aula. No total participaram 268 alunos.

Na primeira etapa foi utilizada entrevista elaborada especialmente para o estudo. Na entrevista, o aluno foi solicitado a indicar três colegas com quem ele mais gostava e três colegas com quem ele menos gostava de brincar e realizar tarefas escolares. Por questões éticas, para que os alunos não percebessem o foco do estudo, também foram realizadas outras questões referentes ao cotidiano escolar, para que o destaque das respostas dadas às questões sobre os alunos mais e menos aceitos fosse minimizado.

Ao término da aplicação das 268 entrevistas, foram realizadas a análise e a tabulação dos dados coletados por meio do programa Excel ${ }^{\circ}$.

\section{$2^{\circ}$ Etapa: Observação Sistemática de Comporta-} mentos

A partir dos resultados alcançados com a primeira etapa da pesquisa foram selecionados os alunos designados como alvo da segunda etapa, ou seja, três alunos com os maiores índices de aceitação e três alunos com os menores índices de aceitação: A1; A3; A5; A9; A11; A13. Os alunos alvo estavam distribuídos nas três escolas ( $A, B$ e C), divididos em seis salas entre o primeiro e o terceiro ano do ensino fundamental.

$\mathrm{Na}$ segunda etapa do estudo foram realizadas observações sistemáticas a partir de protocolo desenvolvido por Freitas e Mendes (2009). Por meio do protocolo foi possível observar o registro dos comportamentos sociais emitidos por cada aluno alvo de forma quantitativa, de acordo com as categorias: a) Frequência comportamental (número de vezes que o comportamento é emitido); b) Direção comportamental em díades interacionais (para quem o comportamento do aluno alvo é direcionado); c) Status predominante das crianças (o aluno alvo está sozinho - $\mathrm{S}$, isolado - I, agrupado - $\mathrm{G}$ ou agrupado em interação - GI); d) Reciprocidade da interação.

Optou-se por realizar a observação sistemática com o preenchimento do protocolo minuto a minuto durante as observações. Para tanto, ao início das observações era acionado o cronômetro e iniciava-se o preenchimento dos comportamentos no protocolo de acordo com a ocorrência dos mesmos durante as observações.

Para garantir a fidedignidade dos dados, aproximadamente $50 \%$ das sessões foram acompanhadas por uma auxiliar de pesquisa, que realizou o mesmo processo de observação sistematizada. Dessa forma, ao longo da tabulação dos dados, nas observações em que houve a participação da auxiliar, eram considerados apenas os registros iguais no preenchimento do instrumento.

Visando maior variabilidade de comportamentos das amostragens do registro, as observações sistemáticas foram realizadas em dias alternados e horários diferentes em cada uma das salas participantes.

Quatro sessões de observação sistemática foram realizadas para cada um dos alunos alvo, com duração de 40 minutos por sessão. Foram desconsiderados cinco minutos das primeiras sessões realizadas com cada aluno alvo, a fim de que os alunos se adaptassem às pesquisadoras os observando. Dessa forma, com as quatro sessões foram totalizados 155 minutos de observação com cada aluno. Considerando que os seis alunos alvo foram observados, realizou-se um total de 930 minutos de observação sistemática.

Com a reunião de todas as informações, foi realizada tabulação dos dados das observações focais por meio do programa Excel ${ }^{\circ}$. Além disso, foi realizada a reunião de análises qualitativas das observações de campo, que serão expostas caracterizando os alunos alvos para melhor entendimento dos dados quantitativos sobre as relações interpessoais estabelecidas na sala de aula e também nas situações de brincadeira, durante o recreio.

\section{RESULTADOS}

Os resultados serão apresentados em duas partes: 1) entrevistas e 2) observações sistemáticas.

\section{Parte 1: entrevistas}

Os resultados da primeira etapa do estudo foram obtidos a partir da aplicação de 268 entrevistas em salas de aula do primeiro ao terceiro ano, nas quais estavam matriculados alunos com DI. As entrevistas foram realizadas com os alunos com DI e seus colegas de sala, 
com o objetivo de identificar preferências, em relação aos colegas, para realização de atividades acadêmicas e de brincadeiras. Após a aplicação dessas entrevistas, foi possível alcançar os índices de aceitação e de rejeição dos alunos com DI.

Os índices de aceitação e rejeição em atividades acadêmicas e de brincadeiras são resultados do total de indicações para o aluno em determinada categoria, em comparação ao total de respostas dadas na sala em que estão matriculados os alunos alvo. Cabe destacar que os resultados correspondem à comparação dos resultados encontrados apenas para os alunos com DI, não sendo realizadas comparações com os demais colegas de sala.

No que diz respeito ao índice de aceitação nas atividades acadêmicas, como pode ser observado no gráfico disposto na Figura 1, seis alunos (A1, A3, A5, A8, A9 e A11) foram citados por seus pares como alguém com quem estes mais gostavam de realizar tarefas escolares.
$\mathrm{Na}$ categoria relacionada à rejeição em atividades acadêmicas, os dados apresentados na Figura 1 evidenciam que nove alunos (A1; A3; A4; A6; A8; A9; A10; A11; A13) foram mencionados como aqueles com quem seus pares menos gostavam de realizar atividades em sala.

$\mathrm{Na}$ categoria aceitação em atividades de brincadeira, conforme apresentado no gráfico disposto na Figura 2, dez alunos (A1; A2; A3; A5; A7; A8; A9; A10; A11; A12) foram indicados. Na última categoria, referente à rejeição em atividades de brincadeira, sete alunos (A3; A9; A6; A8; A10; A11; A13) foram indicados.

Pode-se perceber, por meio dos resultados, que dos treze alunos investigados, dez (A1, A2, A3, A5, A7, A8, $A 9, A 10, A 11, A 12$ e A13) foram citados nas categorias de aceitação, em relação à preferência para brincar, porém seis ( $A 1, A 3, A 5, A 8, A 9$ e A11) foram indicados como pares aceitos para atividades acadêmicas. Sendo assim, alguns que foram citados como pares para brin-

Figura 1. Índice de Aceitação e Rejeição dos Alunos com DI nas Atividades Acadêmicas.

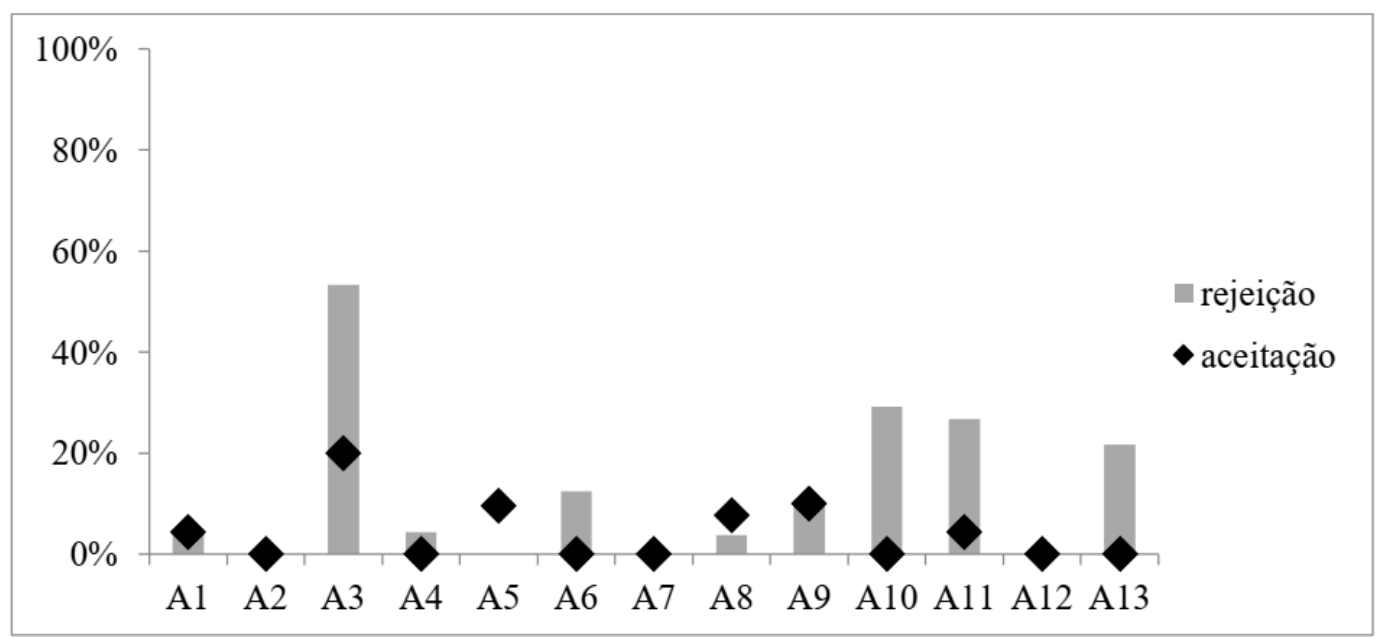

Fonte: dissertação de mestrado defendida pela primeira autora.

Figura 2. Índice de Aceitação e Rejeição dos Alunos Alvo do Estudo nas Atividades de Brincadeira.

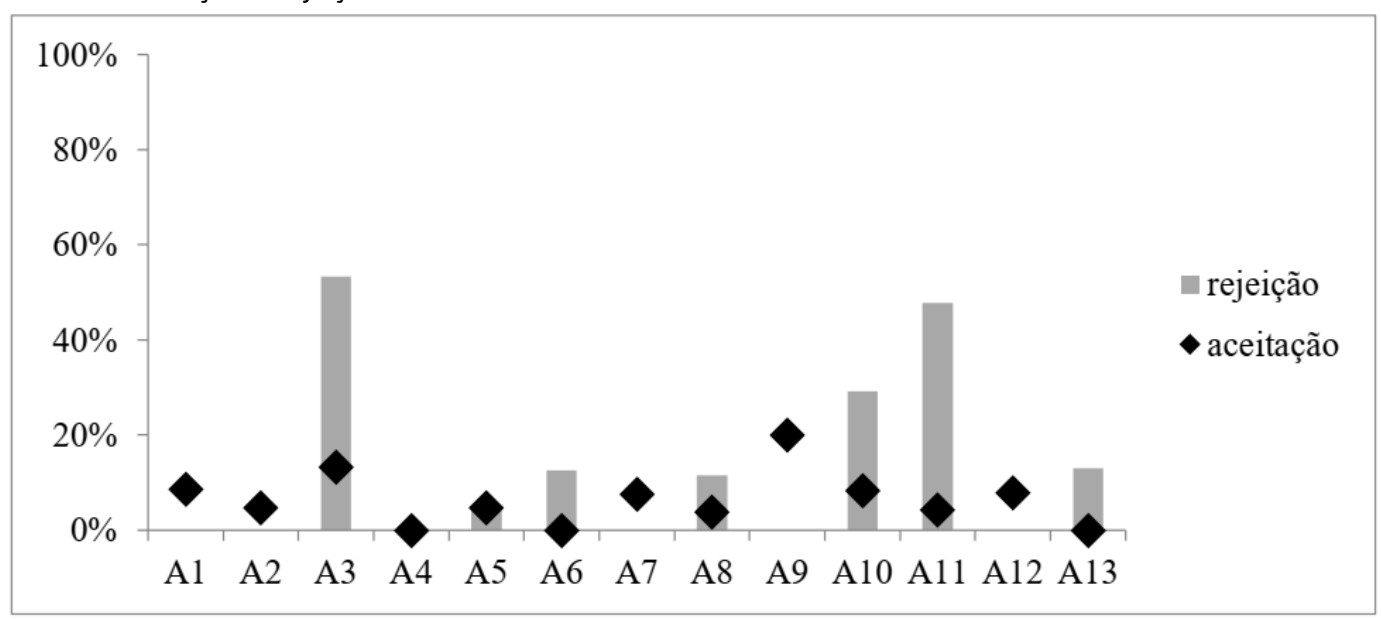

Fonte: dissertação de mestrado defendida pela primeira autora. 
car eram ao mesmo tempo não aceitos para atividades acadêmicas.

Quanto à rejeição, foram citados nove alunos ( $A 1$, A3, A4, A6, A8, A9, A10, A11 e A13) com os quais os colegas não gostariam de realizar atividades acadêmicas e sete colegas ( $A 3, A 5, A 6, A 9, A 11, A 12$ e $A 13)$ com os quais os pares não gostariam de brincar, sendo na maioria os mesmos alunos citados nas duas categorias. Todos os alunos com DI foram indicados em pelo menos uma categoria.

$\mathrm{Na}$ categoria aceitação, os alunos mais indicados para realizar atividades acadêmicas foram: $A 1 ; A 5 ; A 8$ e A9. Quanto à aceitação para brincar, os alunos mais indicados foram: A1; A3; A9; e A10. Por sua vez, nas categorias de rejeição, os alunos A3, A10, A11 e A13 foram indicados como menos aceitos para atividades acadêmicas e os alunos A3, A10, A11 e A13 para as atividades de brincadeira. No total, quatro alunos com maiores índices de aceitação ( $A 1, A 3, A 5$ e $A 9)$ e quatro alunos com maiores índices de rejeição (A3, A10, A11 e A13) foram selecionados para a segunda etapa do estudo.

Considerando que alguns alunos foram selecionados em mais de uma categoria, um total de sete alunos foram eleitos como alvo para a segunda etapa da pesquisa: $A 1 ; A 3 ; A 5 ; A 9 ; A 10 ; A 11$ e A13. No entanto, ao iniciar os procedimentos da Etapa 2, constatou-se que o aluno A10 tinha sido diagnosticado como disléxico, não sendo mais considerado aluno com DI. Participaram então da segunda etapa da pesquisa os alunos $A 1 ; A 3 ; A 5 ; A 9 ;$ A11; e $A 13$, sendo cinco alunos e uma aluna.

\section{Parte 2: observações sistemáticas}

Os resultados qualitativos encontrados a partir da observação sistemática dos alunos alvo ( $A 1 ; A 3 ; A 5$; A9; A11 e A13) proporcionaram o levantamento dos dados que serão apresentados a seguir e no decorrer das discussões.

Todos os alunos participantes da pesquisa tinham diagnóstico de DI e frequentavam a sala de recursos multifuncionais (SRM) de suas escolas. Entre os alunos alvo, três (A1; $A 3$ e A13) tinham apoio educacional em sala de aula. A9 não possuía apoio educacional próprio, mas compartilhava o apoio de um colega.

Os resultados das observações serão expostos a partir das categorias propostas no protocolo de Freitas e Mendes (2009).

$\mathrm{Na}$ análise dos status dos alunos foi possível observar, como apresentado no gráfico disposto na Figura 3, que o status predominante no total das quatro sessões observadas foi na categoria isolado, que indica que os alunos permaneceram mais tempo distante dos colegas e sem apresentar nenhuma interação com os mesmos. Dessa forma, quatro dos seis alunos tiveram esse como o status mais observado: A9 apresentou $67 \%$ do tempo total isolado de interações com seus colegas; A1 e A13 permaneceram isolados durante $60 \%$ do tempo total; A11 ficou isolado durante $59 \%$ do tempo total. Cabe destacar que A3 permaneceu o menor tempo (18\%) de forma isolada.

A aluna $A 5$ foi a que mais apresentou o status sozinho (S), o que indica que a mesma estava distante dos colegas, sendo $28 \%$ do tempo total de observações.

O segundo status mais recorrente durante as observações foi o de agrupado em interação (GI), caracterizado por episódios nos quais o sujeito está próximo de outros colegas e envolvido em alguma atividade. $O$ aluno A3 e a aluna $A 5$ foram os que mais permaneceram nesse status, com respectivamente $46 \%$ e $37 \%$ do tempo total de observações. Os alunos A1 e A9 foram os que menos apresentaram status $\mathrm{GI}$ com respectivamente $14 \%$ e $16 \%$

Figura 3. Gráfico da Frequência de Status dos Alunos Alvo nas Observações Focais.

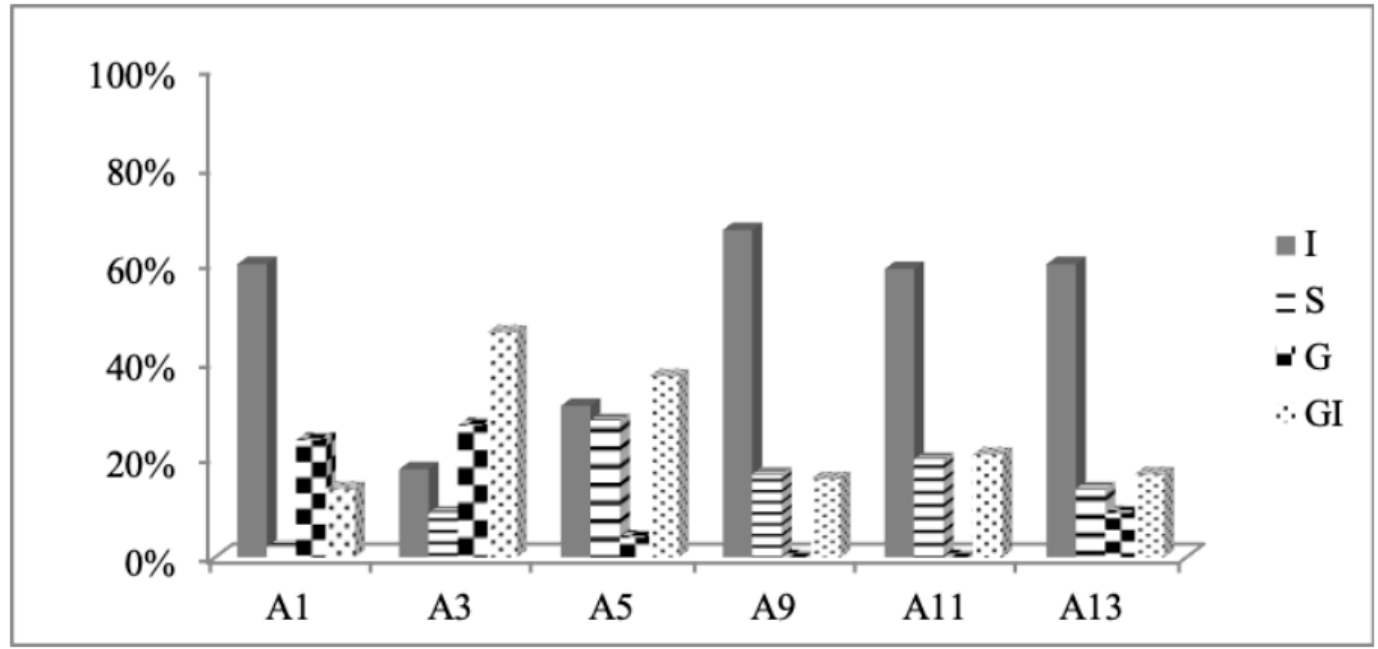

Fonte: dissertação de mestrado defendida pela primeira autora. 
do tempo total de observações. A categoria agrupado (G), que indica que o aluno alvo estava próximo dos colegas, mas sem interação social, foi a categoria menos observada nas sessões.

Em relação às iniciativas interacionais, os alunos $A 1$, A9, A11 e A13 obtiveram, na direção do aluno alvo para o seu colega de sala (ÇA-Ç), maior número de iniciativas ignoradas do que respondidas, respectivamente, $83 \%$, $77 \%, 62 \%$ e $73 \%$. O aluno A3 obteve um total de $51 \%$ de suas iniciativas interacionais ignoradas, número próximo aos $49 \%$ de iniciativas respondidas.

No que diz respeito à análise da direção Ç-ÇA (comportamentos dos colegas em direção à criança alvo) de iniciativas interacionais respondidas e ignoradas, conforme mostra o gráfico disposto na Figura 4 , destaca-se que os colegas de A5 obtiveram $70 \%$ de suas iniciativas respondidas, contrapondo-se a $30 \%$ de iniciativas ignoradas por A5. Por sua vez, os colegas de A3 obtiveram um total de $56 \%$ de iniciativas respondidas em contrapartida a $44 \%$ ignoradas. Os colegas de A1, A9, A11 e A13 obtiveram mais iniciativas ignoradas do que respondidas.

\section{DISCUSSÃO}

Constatou-se a partir dos resultados da primeira parte da pesquisa, que a maioria dos alunos obteve maiores índices de rejeição do que aceitação, tanto em atividades acadêmicas como de brincadeiras, assim como alguns outros estudos semelhantes realizados anteriormente (Casado, 2012; Baleotti, 2006).

Batista e Enumo (2004) afirmam que a não aceitação dos alunos com $\mathrm{DI}$, por parte de seus colegas, indica que a inclusão escolar não está acontecendo, já que não há trocas sociais que beneficiem mutuamente os alunos com e sem deficiência.

Os resultados da primeira etapa da pesquisa indicam que as relações interpessoais entre os alunos com DI e seus pares podem não estar sendo satisfatórias, já que aqueles foram indicados como mais rejeitados do que aceitos por seus colegas de sala de aula o que traz implicações para o desenvolvimento dos planejamentos e planos de aula, segundo as considerações da BNCC.

Em relação ao desenvolvimento acadêmico, Del Prette e Del Prette (2005) explicam que as relações interpessoais estão intimamente relacionadas com os processos de ensino e aprendizagem, pois é a partir das relações interpessoais que a criança vai aprender a conviver assertivamente em sociedade, aprendendo a se comportar nos ambientes e tornando esse ambiente propício ao seu desenvolvimento. Em vista disso, os resultados do presente estudo são preocupantes, já que relações interpessoais não satisfatórias no ambiente escolar podem influenciar de modo negativo o desenvolvimento das habilidades acadêmicas.

Como forma de melhor analisar os resultados apresentados a partir da observação sistemática realizada com os alunos alvo, a discussão será dividida em dois tópicos.

A influência do apoio educacional (AE) e das professoras regentes nas relações interpessoais em sala de aula

Os alunos A1 e A13, que apresentaram $60 \%$ do status como isolado, estavam isolados também fisicamente dos colegas em sala de aula, sentados ao fundo entre a parede e seus apoios educacionais. A interação com seus colegas era necessariamente mediada por seus AEs, que permitiam ou não que os alunos se comunicassem e controlavam até mesmo se os alunos poderiam sair de suas carteiras, mesmo que houvesse outros alunos caminhando e conversando pela sala. No recreio também foi observado que os AEs cuidavam dos alunos $A 1$ e A13, interferindo em suas relações interpessoais com os colegas. Resultados semelhantes foram descritos no

Figura 4. Gráfico de Iniciativas Interacionais Respondidas (I*) e Ignoradas (I) nas Direções ÇA-ÇE Ç-ÇA.

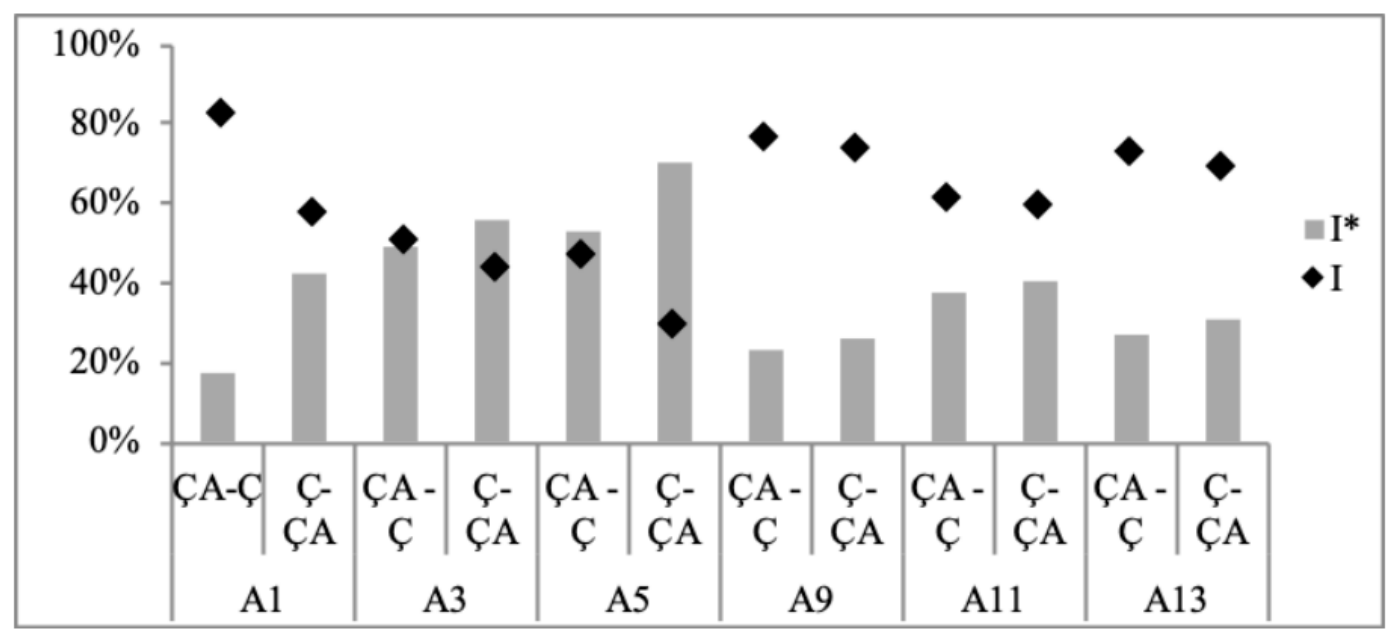

Fonte: dissertação de mestrado defendida pela primeira autora. 
estudo conduzido por Matos e Mendes (2014).

O aluno A3 também possuía apoio educacional, porém ao longo das sessões foram observadas situações muito diferentes das vivenciadas por A1 e A13: A3 passou $46 \%$ das sessões de observação com status de agrupado em interação (GI).

A3 também fazia parte de uma sala dinâmica como a de $\mathrm{A} 1$ e A13. Em quatro das observações, A3 estava sentando na primeira carteira, com colegas ao seu lado e atrás dele e a mesa da professora logo mais à frente. Em duas outras sessões ainda teve a presença de um colega sentado ao seu lado.

A apoio educacional (AE) de $A 3$, ao longo de todas as sessões, trabalhou de forma articulada com a professora regente. Tanto a professora regente como a AE incentivavam que $o$ aluno realizasse as tarefas, mas também não o impediam de circular pela sala, conversando ou solicitando material para os colegas, uma vez que outros alunos também tinham esse comportamento.

Durante a observação do recreio de $A 3$, a apoio educacional do aluno foi para a sala dos professores junto com a professora regente da sala, e o aluno ficava livre para brincar com seus colegas sem nenhuma supervisão. Tal fato pode contribuir de forma decisiva para o bom relacionamento observado entre $A 3$ e seus colegas de sala.

\section{Relações interpessoais e habilidades sociais}

No status de A3 pode ser observado que este passou mais tempo em interações com seus colegas que a maioria dos alunos alvo; estava incluído em uma sala dinâmica em que os alunos se relacionavam o tempo todo. O próprio aluno alvo tinha uma boa relação com um colega, que em algumas observações sentava-se ao dele. No entanto, A3 obteve um total de $51 \%$ de suas iniciativas ignoradas. $\mathrm{O}$ aluno, por mais que tentasse se relacionar com alguns colegas, era muitas vezes ignorado por apresentar comportamentos inapropriados como falar alto ou interromper os colegas enquanto esses estavam em atividade.

Del Prette e Del Prette (2005) afirmam que crianças com DI podem ter limitações próprias que comprometem tanto o acesso como o processamento cognitivo da estimulação social do ambiente, tendo maiores dificuldades para desempenhar respostas socialmente competentes em diferentes situações. Os autores acrescentam que para o desempenho socialmente competente é necessário que a criança identifique as demandas do ambiente social e com essas informações consiga elaborar e monitorar o seu próprio comportamento.

A aluna $A 5$, que na primeira etapa da pesquisa já tinha sido indicada como a segunda aluna mais aceita para a realização de atividades acadêmicas, apresentou na segunda etapa realmente ter relações interpessoais mais estabelecidas com seus colegas. $\mathrm{Na}$ categoria de status ela teve maior frequência para a categoria de agrupado em interação (GI) e foi a única a obter um maior número de iniciativas interacionais respondidas do que ignoradas pelos seus colegas (ÇA-Ç). Em comparação aos alunos alvo, A5 também se destacou por responder cerca de $70 \%$ das iniciativas interacionais de seus colegas.

A sala de aula de $\mathrm{A} 5$ era um ambiente dinâmico onde as crianças podiam ir até a mesa dos colegas e realizar atividades conjuntamente. A aluna sentava cercada de colegas e em vários momentos da observação estava acompanhada de uma colega que lhe ajudava a fazer a tarefa, com o incentivo de sua professora para essas atividades conjuntas. A professora de A5 circulava o tempo todo pela sala, verificando mesa a mesa a realização das atividades, além de receber e orientar os alunos que a solicitavam.

Segundo Del Prette e Del Prette (2005), um repertório desenvolvido em habilidades sociais é decisivo para construção de relações interpessoais harmônicas entre crianças. Segundo os autores, são a base do desenvolvimento dessas relações, habilidades relacionadas à comunicação, expressividade e desenvoltura que contribuem para gerar amizades, respeito e um convívio harmônico mais positivo.

Na primeira parte do estudo, o aluno A9 obteve o maior índice de aceitação por parte de seus colegas para atividades de brincadeira, com índice de $20 \%$ do total de respostas de seus colegas. Por sua vez, na categoria de atividades acadêmicas, ele recebeu $10 \%$ das indicações totais tanto para aceitação quanto para rejeição.

A partir da segunda parte do estudo, por meio da observação sistemática, foi possível verificar que A9 obteve $67 \%$ para o status isolado (I), sendo dentre os alunos alvo o que mais se classificou para esse status. Ou seja, permaneceu a maior parte das observações longe dos colegas e sem apresentar nenhuma interação.

Diferentemente das outras salas, a turma de A9 era composta por alunos que pouco interagiram entre si, já que nas aulas observadas a tarefa exigia que eles passassem a maior parte do tempo copiando e a professora regente ficava pedindo silêncio constantemente. Dessa forma, dentre as salas investigadas, a turma de A9 era a mais restritiva para o estabelecimento de relações interpessoais, o que pode ter influenciado para que ele tenha permanecido a maioria das observações sistemáticas como isolado.

A partir das observações sistemáticas, foi possível notar que muito dos manejos de sala de aula da aluna A5 poderiam também ser utilizados para melhorar as relações interpessoais dos alunos A9, A11 e A13. Como por exemplo, o incentivo à condução de atividades escolares conjuntas entre os alunos e o favorecimento de relações interpessoais mais assertivas entre alunos alvo e colegas de sala. 
A partir dos resultados desse trabalho pode-se perceber que as relações interpessoais dos alunos analisados na segunda etapa do estudo, estão em sua maioria sendo pouco desenvolvidas. Isso não implica em dizer que a inclusão escolar não esteja ocorrendo, mas sim em apontar, com base no que foi observado, que o ambiente da sala de aula como um todo precisa de modificações que beneficiem não só as relações interpessoais entre alunos com deficiência e seus colegas, mas também as relações entre todos os alunos entre si, assim como as relações entre os profissionais da escola e os alunos.

Além disso, foi possível observar que muitos fatores influenciam para o estabelecimento de suas interações sociais. Dentre eles a posição em sala de aula, o manejo do professor regente, o auxílio do apoio educacional em sala, as características do aluno com DI, a competência social dos alunos com $\mathrm{DI}$, bem como a competência social de seus colegas de sala.

Foi possível observar como professores regentes e apoios educacionais têm influência direta para o estabelecimento das relações interpessoais entre os alunos com DI. Destaca-se a necessidade de outros estudos sobre as relações interpessoais estabelecidas entre professores e alunos com DI, apoios pedagógicos e alunos em sala de aula e apoios educacionais e professores.

A pesquisa possibilitou compreender que, para a melhoria da prática da inclusão escolar, é preciso o desenvolvimento de pesquisas sobre os indicadores de como estão os alunos com DI incluídos, a fim de embasar contribuições referentes a cada realidade, para que a longo prazo se construa uma nova cultura de inclusão escolar. Além disso, espera-se, com os resultados do presente estudo, contribuir para o desenvolvimento das competências socioemocionais e, de forma concreta, segundo se conclui a partir desse estudo, das competências social e interpessoal.

\section{REFERÊNCIAS}

Baleotti, L. R. (2006). Um estudo do ambiente educacional inclusivo: descrição das atitudes sociais em relação à inclusão e das relações interpessoais. (Tese de Doutorado). Universidade Estadual Paulista Júlio de Mesquita Filho, UNESP, Marília-SP.

Batista, M. W.; Enumo, S. R. F. (2004). Inclusão escolar e deficiência mental: análise da interação social entre companheiros. Estudos de psicologia, 9(1), p. 101-111.

Ministério da Educação [MEC] (2017). Base Nacional Comum Curricular. Brasília: Ministério de Educação. Recuperado de: http://portal.mec.gov.br/index.php?option=com_ docman\&view $=$ download \&alias $=79601$-anexo-textobncc-reexportado-pdf-2\&category_slug=dezembro-2017pdf\&Itemid=30192.

Casado, C. de C. (2012). Interações e relações de amizade: um estudo longitudinal no contexto de uma escola inclusiva (Tese de doutorado). Programa de Pós-Graduação em Teoria e Pesquisa do Comportamento da Universidade Federal do Pará, Belém-PA.

Del Prette, A.; Del Prette, Z. A. P. (2005). Psicologia das habilidades sociais na infância: Teoria e Prática. Petrópolis: Vozes.

Definition and Selection of Competencies: Theoretical and Conceptual Foundations [DeSeCo] (2016). Determinação e Seleção de Competências. Recuperado de http://deseco. $\mathrm{ch} /$

Freitas, M. C.; Mendes, E. G. (2009). Interação entre uma criança com deficiência e seus pares em uma creche regular. Revista Educação Especial, 22(35), 339-350.

Matos, S. N.; Mendes, E. G. (2014). Demandas decorrentes da inclusão escolar. Revista Educação Especial, 27(48), p. $27-40$.

Rosin-Pinola, A. R.; Del Prette, Z. A. P.; Del Prette, A. (2007). Habilidades sociais e problemas de comportamento de alunos com deficiência mental, alto e baixo desempenho acadêmico. Revista Brasileira de Educação Especial, 13(2), p. 239-256.

Sebastián-Heredero, E. (2016) Reconstruyendo el currículo del siglo XXI: escuela inclusiva o escuela para todos. In: J. L. Bizelli; E. Sebastian-Heredero; P. R. M. Ribeiro (Eds.), Inclusão e aprendizagem. (Vol 1, pp. 15-22). São Paulo: Cultura Editora.

O presente estudo contou com o apoio financeiro da Fundação de Apoio ao Desenvolvimento do Ensino, Ciência e Tecnologia do Estado de Mato Grosso do Sul (FUNDECT/MS). 